\title{
Polymer-solvent interaction parameters of SBS rubbers by inverse gas chromatography measurements
}

\author{
E. Díez*, G. Ovejero, M.D. Romero, I. Díaz

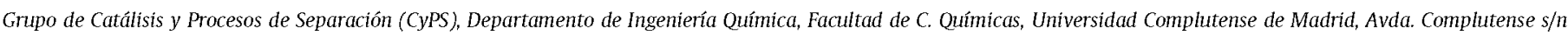 \\ 28040 Madrid, Spain
}

Keywords:

SBS triblock copolymers

Inverse gas chromatography

Solubility parameter

Flory-Huggins parameter

\begin{abstract}
A B S T R A C T
The solubility parameters of two SBS commercial rubbers with different structures (lineal and radial), and with slightly different styrene content have been determined by inverse gas chromatography technique. The Flory-Huggins interaction parameters of several polymer-solvent mixtures have also been calculated. The influence of the polymer composition, the solvent molecular weight and the temperature over these parameters have been discussed; besides, these parameters have been compared with previous ones, obtained by intrinsic viscosity measurements. From the Flory-Huggins interaction parameters, the infinite dilution activity coefficients of the solvents have been calculated and fitted to the wellknown NRTL model. These NRTL binary interaction parameters have a great importance in modelling the separation steps in the process of obtaining the rubber.
\end{abstract}

\section{Introduction}

In the polymer industry, there is a wide range of materials which can be named as styrene-butadiene rubbers (SBR); this group includes polymers with different molecular weights, but also with different monomer ratios.

For this reason, depending on the final purpose of the material, these two previous variables can be modified in order to enhance different properties, such as thermal resistance or Young's module. But the thermodynamic properties, as well as the polymer-solvent compatibility, can also vary when the polymer structure or the styrene content are modified [1].

The polymer-solvent compatibility is extremely important to determine the suitability of the rubber for different applications, as well as to design or model rubber production processes. In this last case, thermodynamic data are especially relevant to analyze the separation steps, which are usually carried out either by devolatilization or steam stripping, being both of them equilibrium-staged processes [2].

Measuring polymer-solvent phase equilibrium is not a simple task, because of the specific properties of these polymer-solvent mixtures. In a conventional binary mixture, the relative sizes of the molecules of both components are close to each other; but in a polymer-solvent mixture, there is a large difference between the sizes of the molecules of both components. Therefore, to obtain accurate thermodynamic information, non-conventional techniques as swelling [3] inverse gas chromatography (IGC) [4,5] or intrinsic viscosity (IV) [6] are required.

In previous works, we developed a thermodynamic study with a SEBS (styrene-ethylene/butadiene-styrene) rubber, by using intrinsic viscosity and inverse gas chromatography measurements $[7,8]$. Afterwards, we have started to study SBS rubbers by means of IV measurements [9] and, in this paper, the polymer-solvent interactions between two SBS rubbers and several solvents have been analyzed by means of inverse gas chromatography. The importance of this study is because the interactions between both components (polymer and solvent) might change with their relative amount in the mixture: while IV technique is related to an infinite diluted polymer solution, IGC technique is related to an infinite diluted solvent solution.

The reference model which has been employed to model the phase equilibrium of these SBS-solvent mixtures is the wellknown Flory-Huggins theory [10]. In this theory, the key point is the calculation of the Flory-Huggins interaction parameter $(\chi)$ or polymer-solvent interaction parameter. Although this value was originally defined as independent of the composition, many authors have claimed that the effect of composition is not negligible [11,12]. Therefore, it is really important to determine the polymer-solvent interaction parameters values with different techniques, so that thermodynamic information of the opposite composition extremes of a polymer-solvent mixture can be obtained.

Additionally, the Flory-Huggins theory allows calculating the solubility parameter of the polymer [13]. The importance of this parameter is due to, nowadays, is considered as a criteria for 
selecting a suitable solvent in industry, and for predicting solubility, degree of swelling or polymer compatibility. Finally, from the Flory-Huggins theory, $P-w_{i}$ (pressure vs, solvent $i$ mass fraction) equilibrium data can be obtained and fitted to the well-known NRTL model [14] in a relatively simple way, as previously was shown in the literature [2]. The binary interaction parameters of this model are really useful in order to simulate the separation steps in the process of obtaining the rubber [2].

Thus, the aim of this work is to study the polymer-solvent phase equilibrium of two SBSs (one with linear structure, and one with radial or star structure) in the low solvent compositions area and, also, to analyze the influence of the relative amount of polymer in the mixture over the interaction parameters by comparing the results presented here with the previously reported ones.

\section{Experimental}

\subsection{Materials}

SBS copolymers were synthesized and supplied by Alfonso Cortina Technology Center of REPSOL-YPF under the names C411 (radial structure) and C501 (linear structure). The styrene contents of both rubbers are $30 \%$ and $31 \%(\mathrm{w} / \mathrm{w})$ respectively. The weight-average molecular weight of $C 411$ is $237,000 \mathrm{~kg} / \mathrm{kmol}$ whereas the one of $C 501$ is $113,000 \mathrm{~kg} / \mathrm{kmol}$. The density of both materials was measured by means of intrusion mercury porosimetry and the obtained values for C411 and C501 were $908 \mathrm{~kg} / \mathrm{m}^{3}$ and $929 \mathrm{~kg} / \mathrm{m}^{3}$, respectively.

All the employed solvents were analytical grade and were purchased from Aldrich. They were used directly, without any purification step. Chromosorb W/AW-DMCS 80-100 mesh was also purchased from Aldrich.

\subsection{Experimental procedure}

The stationary phase used in this work was prepared by dissolving a weighted sample of the polymer in cyclohexane and depositing the solution on a weighted amount of support. The mixture was allowed to dry by slow evaporation in a rotavapor under vacuum, while being stirred to ensure homogeneous mixture; evaporation time was $8 \mathrm{~h}$. The final amount of each polymer deposited in the support was determined by thermogravimetric analysis on a Seiko EXSTAR 6000 TG/DTA 6200 equipment. Each analysis was repeated, and the average value was selected in each case. The obtained percentages were $9.15 \%(w / w)$ for $C 411$ rubber and $11.55 \%(\mathrm{w} / \mathrm{w})$ for $\mathrm{C} 501$ rubber.

Afterwards, the coated support was packed into a $1 / 4$ in. nominal diameter and $1.9 \mathrm{~m}$ length column, which was installed in a VARIAN 3800 gas chromatography, equipped with a thermal conductivity detector and an electronic flow controller.

All the measurements were carried out with a helium flow of $30 \mathrm{~mL} / \mathrm{min}$, as carrier gas, and air, as inert component, in a temperature range between 30 and $60^{\circ} \mathrm{C}$. In the literature, typical values of the amount of injected solvent (to consider that infinite dilution takes place) range between $0.1 \mu \mathrm{L}$ and $0.3 \mu \mathrm{L}[15,16]$. In this study we have worked with an intermediate value $(0.2 \mu \mathrm{L}$ of solvent plus $0.8 \mu \mathrm{L}$ of inert gas), which is adequate to assume infinite dilution. As an example, in the case of the C411 column, the total amount of polymer packed into the column was $0.0117 \mathrm{~g}(12.085 \mathrm{~g}$ of total solid, with a polymer content of $9.15 \%(w / w))$, and the amount of injected solvent in each experiment was exactly $0.2 \mu \mathrm{L}$. If we consider cyclohexane as solvent (whose density, at $30^{\circ} \mathrm{C}$, is $0.758 \mathrm{~g} / \mathrm{mL}$ ), the overall solvent mass injected in each experiment was $0.000000152 \mathrm{~g}$. So, the solvent mass fraction in the studied system was:

$$
\begin{aligned}
w_{\text {solvent }} & =\frac{\text { mass of solvent }}{\text { mass of solvent }+ \text { mass of polymer }} \\
& =\frac{0.000000152}{0.000000152+0.0117}=0.000013
\end{aligned}
$$

which is close to the lowest detection limit of conventional analytical instruments.

\subsection{IGC basis}

According to IGC technique [17], in a solvent (1)-polymer (2) mixture, the relation between the infinite dilution activity coefficient of the solvent, $\left(\Omega_{1}^{\infty}\right)_{I G C}$, and its retention volume $\left(V_{g}\right)$, is given by Eq. (1), where $T$ is the temperature in $\mathrm{K}, R$ is the ideal gas constant, $M_{1}$ is the solvent molecular weight and $f_{1}^{0}$ is the standard fugacity of the solvent. Usually this last value is calculated by means of the Virial EOS truncated after the second term, as shown in Eq. (2).

$\ln \left(\Omega_{1}^{\infty}\right)_{\mathrm{IGC}}=\ln \left(\frac{R T}{V_{g} M_{1} f_{1}^{0}}\right)$

$\ln \left(\Omega_{1}^{\infty}\right)_{\mathrm{IGC}}=\ln \left(\frac{R T}{V_{g} M_{1} p_{1}^{0}}\right)-\frac{\left(B_{11}-V_{1}\right) p_{1}^{0}}{R T}$

In this last equation, $B_{11}$ is the solvent second term of the Virial EOS, $p_{1}^{0}$ is the solvent vapor pressure and $V_{1}$ is the solvent molar volume.

The specific retention volume of the solvent $\left(V_{g}\right)$ is given by Eq. (3), where $F$ is the flow rate of the carrier gas corrected to the column temperature, $t_{r}$ is the retention time of the solvent, $t_{m}$ is the retention time of the inert, $W_{s}$ is the amount of polymer packed in the column and $j$ is a correction factor. Due to the carrier gas is compressible, the pressure drop along the column might cause an increase of the volume flow rate in the outlet $\left(P_{0}\right)$ compared with the inlet value $\left(P_{i}\right)$; therefore, a correction factor $(j)$ is usually added (Eq. (4)) [17].

$V_{g}=\frac{j\left(t_{r}-t_{m}\right) F}{W_{s}}$

$j=\frac{3}{2} \frac{\left(P_{i} / P_{0}\right)^{2}-1}{\left(P_{i} / P_{0}\right)^{3}-1}$

In this work, molar volumes have been calculated according to the Rackett model modified by Spencer and Danner [18], the second terms of Virial EOS have been calculated with Tsonopoulos' correlation [19], and the solvent vapor pressure values have been taken from the literature [20].

From the values of infinite dilution activity coefficient, the Flory-Huggins interaction parameter $(\chi)$ can be calculated by using Eq. (5) [21], where $r$ is the ratio between molar volume of the polymer divided by the molar volume of the solvent, and $\rho_{1}$ and $\rho_{2}$ are the solvent and polymer densities, respectively. Equivalent expressions have been employed in the literature [22]

$\chi=\ln \left(\Omega_{1}^{\infty}\right)_{\mathrm{IGC}}-\left(1-\frac{1}{r}\right)+\ln \frac{\rho_{1}}{\rho_{2}}$

This last equation is directly derived from the combination of Eq. (2) with the well-known Flory equation [10] (Eq. (6)), which allows calculating the activity of a solvent, in a polymer-solvent mixture:

$\ln \left(a_{1}\right)=\ln \left(1-\Phi_{2}\right)+\left(1-\frac{1}{r}\right) \Phi_{2}+\chi \Phi_{2}^{2}$

On the other hand, Hildebrand and Scout [23], developed a regular solution model defining the solubility parameter of one 
compound $i$ as the square root of the cohesive energy, which can be calculated from heat of vaporization values (Eq. (7)).

$\delta_{1}=\left[\frac{\Delta_{\mathrm{vap}} H_{1}-R T}{V_{1}}\right]^{0.5}$

The Flory-Huggins theory, modified by Blanks and Prausnitz [13], allows establishing a relation between Flory-Huggins parameter $(\chi)$ and the solubility parameters of polymer $\left(\delta_{2}\right)$ and solvents $\left(\delta_{1}\right)$, where $\chi_{s}$ is the entropic contribution to $\chi$ (Eq. (8)). The value of $\chi_{S}$ is usually kept constant and equal to 0.34 .

$\chi=\chi_{s}+\frac{V_{1}}{R T}\left(\delta_{1}-\delta_{2}\right)^{2}$

Rearranging terms, Eq. (9), is obtained, so the polymer solubility parameters can be determined from the slope of $\left[\left(\delta_{1}^{2} / 2\right)-\right.$ $\left.\left(\chi R T / 2 V_{1}\right)\right]$ vs. $\delta_{1}$, by simply knowing the solubility parameter of the solvent [24].

$\left(\frac{\delta_{1}^{2}}{2}-\frac{\chi R T}{2 V_{1}}\right)=\delta_{2} \delta_{1}-\left(\frac{\delta_{2}^{2}}{2}+\frac{\chi_{S} R T}{2 V_{1}}\right)$

Finally, from the activity coefficient values at several temperatures, the values of the heats of vaporization of the solvent $\left(\Delta_{\mathrm{vap}} H_{1}\right)$ can be obtained (Eq. (10)) by calculating the heats of solution $\Delta_{S} H_{1}$ (Eq. (11)) and the partial molar heats of mixing $\Delta_{\text {mix }} H_{1}^{\infty}$ (Eq. (13)) [21]:

$\Delta_{\text {vap }} H_{1}=\Delta_{\text {mix }} \bar{H}_{1}^{\infty}-\Delta_{\mathrm{s}} H_{1}$

$\Delta_{\mathrm{s}} H_{1}=-R\left[\frac{\partial\left(\ln \left(V_{\mathrm{g}}^{\mathrm{O}}\right)\right)}{\partial(1 / T)}\right]$

$V_{g}^{0}=V_{g}\left(\frac{273.15}{T}\right)$

$\Delta_{\text {mix }} H_{1}^{\infty}=R\left[\frac{\partial\left(\ln \left(\Omega_{1}^{\infty}\right)\right.}{\partial(1 / T)}\right]$

These values, derived from the experimentally determined activity coefficients, can be compared with the ones estimated employing the Watson model [25] as a consistency test, in order to check its goodness.

\section{Results and discussion}

\subsection{Flory-Huggins parameter values}

Tables 1 and 2 show the measured values of the retention volumes $\left(V_{g}\right)$, along with the calculated values of the infinite dilution solvent activity coefficients, $\left(\Omega_{1}^{\infty}\right)_{\text {IGC }}$, and the Flory-Huggins interaction parameters $(\chi)$, for the binary mixtures of both C501 and C411 rubbers with different solvents, in the temperature range from $30^{\circ} \mathrm{C}$ to $60^{\circ} \mathrm{C}$.

The Flory-Huggins interaction parameter is a measurement of the compatibility of a polymer-solvent pair so that, the lower the Flory-Huggins parameter, the higher the compatibility. According to the literature [24], values below 0.5 (critical $\chi$ parameter for high molecular weight polymers) suggest total miscibility of the polymer in the solvent. The mixtures of cyclopentane and benzene with both C401 and C501 rubbers are close to this critical value but, for the second rubber (C501), its mixtures with cyclohexane, toluene, methylcyclohexane and tetrahydrofuran also show total miscibility. Toluene and tetrahydrofuran are the best solvents for this last rubber (C501), as their values of the $\chi$ parameter are the lowest ones. The worst solvents for both rubbers are $n$-pentane, $n$-hexane, and $n$-heptane, because of the high values of the Flory-Huggins parameter.

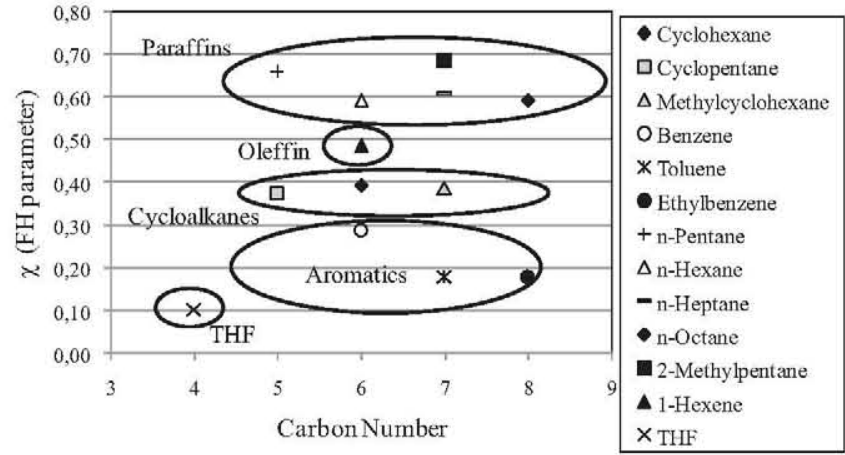

Fig. 1. Influence of molecular weight over $\chi$ for $\mathrm{C} 411$ polymer at $30^{\circ} \mathrm{C}$.

Regarding its dependence with temperature, the $\chi$ parameter should theoretically decrease when the temperature increases [10] but, as it can be seen in Tables 1 and 2, this behavior does not happen for the systems studied here. This is in agreement with other works $[8,21]$. In fact, Tables 1 and 2 show that, in the majority of the mixtures, the temperature dependence is almost negligible.

According to Blanks and Prausnitz [13], the Flory-Huggins parameter has two contributions: one entropic and one enthalpic. The first one is related to the free volume of the solvent, so it is expected to increase with temperature, because the free volume of the solvent also increases with temperature. The second one is related to the intermolecular forces between the polymer and the solvent, so it is expected to decrease with temperature, due to the decrease of these interactions. Therefore, the overall dependence of the Flory-Huggins parameter on temperature will depend on the prevailing effect.

The influence of the carbon number is shown in Figs. 1 and 2. As it can be observed, the mixtures of both rubbers with the aromatic compounds have the lowest values of the Flory-Huggins parameters and the mixtures with paraffin-type compounds have the highest values of this parameter. This behavior is relatively logical taking into account the aromatic and oleffinic character of the SBS rubber. Similar results were obtained in a previous IGC work with a styrene-ethylene/butadiene-styrene rubber [8]. In the case of the $\mathrm{C} 501$ mixtures, it can also be noticed that, for a same family of compounds, the Flory-Huggins interaction parameter increases with molecular weight.

\subsection{Solubility parameter values}

Once the Flory-Huggins parameters were calculated, the solubility parameter of the two rubbers were determined from the slope of the plot $\left[\left(\delta_{1}^{2} / 2\right)-(\chi R T) / 2 V_{1}\right]$ vs. $\delta_{1}$ (Eq. (9)). As an exam-

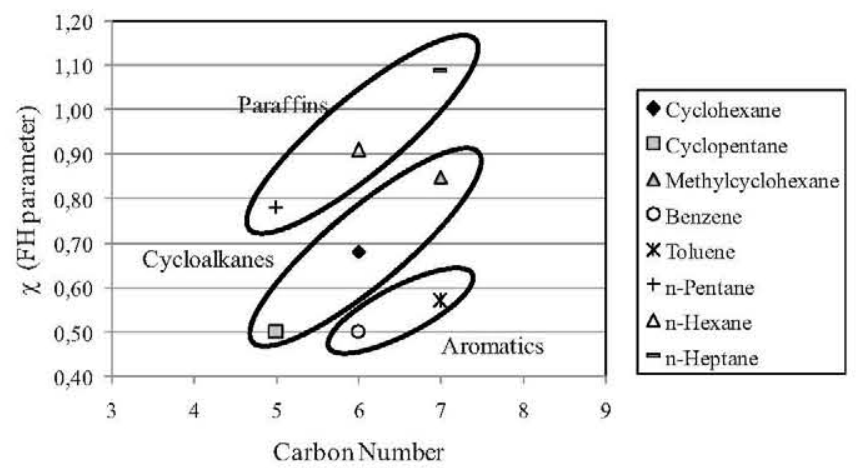

Fig. 2. Influence of molecular weight over $\chi$ for $\mathrm{C} 501$ polymer at $30^{\circ} \mathrm{C}$. 
Table 1

Experimental results for $\mathrm{C} 501$ rubber.

\begin{tabular}{|c|c|c|c|c|c|c|c|c|c|c|c|c|}
\hline \multirow[t]{3}{*}{ Solvent } & \multicolumn{12}{|c|}{ C501 polymer } \\
\hline & \multicolumn{4}{|c|}{$V_{g}\left(\mathrm{~cm}^{3} / \mathrm{g}\right)$} & \multicolumn{4}{|c|}{$\left(\Omega_{i}^{\infty}\right)_{\mathrm{IGC}}$} & \multicolumn{4}{|l|}{$x$} \\
\hline & $30^{\circ} \mathrm{C}$ & $40^{\circ} \mathrm{C}$ & $50^{\circ} \mathrm{C}$ & $60^{\circ} \mathrm{C}$ & $30^{\circ} \mathrm{C}$ & $40^{\circ} \mathrm{C}$ & $50^{\circ} \mathrm{C}$ & $60^{\circ} \mathrm{C}$ & $30^{\circ} \mathrm{C}$ & $40^{\circ} \mathrm{C}$ & $50^{\circ} \mathrm{C}$ & $60^{\circ} \mathrm{C}$ \\
\hline$n$-Pentane & 42 & 31 & 22 & n.a. & 9.02 & 9.14 & 9.67 & n.a. & 0.78 & 0.79 & 0.81 & n.a. \\
\hline$n$-Hexane & 122 & 82 & 58 & 41 & 9.71 & 10.04 & 10.32 & 10.64 & 0.91 & 0.93 & 0.94 & 0.96 \\
\hline$n$-Heptane & 349 & 222 & 148 & 102 & 11.18 & 11.49 & 11.69 & 11.84 & 1.09 & 1.10 & 1.11 & 1.10 \\
\hline Cyclopentane & 105 & 76 & 54 & n.a. & 5.70 & 5.65 & 5.96 & n.a. & 0.50 & 0.48 & 0.52 & n.a. \\
\hline Cyclohexane & 283 & 189 & 130 & 93 & 6.58 & 6.75 & 6.94 & 6.99 & 0.68 & 0.70 & 0.71 & 0.71 \\
\hline Methylcyclohexane & 494 & 321 & 218 & 153 & 7.84 & 7.97 & 8.03 & 8.08 & 0.85 & 0.86 & 0.85 & 0.84 \\
\hline Benzene & 394 & 255 & 177 & 125 & 4.85 & 5.07 & 5.10 & 5.18 & 0.50 & 0.53 & 0.53 & 0.53 \\
\hline Toluene & 1172 & 747 & 476 & 321 & 5.25 & 5.30 & 5.52 & 5.63 & 0.57 & 0.57 & 0.60 & 0.61 \\
\hline
\end{tabular}

n.a.: not available.

Table 2

Experimental results for $\mathrm{C} 411$ rubber.

\begin{tabular}{|c|c|c|c|c|c|c|c|c|c|c|c|c|}
\hline \multirow[t]{3}{*}{ Solvent } & \multicolumn{12}{|c|}{ C411 polymer } \\
\hline & \multicolumn{4}{|c|}{$V_{g}\left(\mathrm{~cm}^{3} / \mathrm{g}\right)$} & \multicolumn{4}{|c|}{$\left(\Omega_{i}^{\infty}\right)_{\mathrm{IGC}}$} & \multicolumn{4}{|l|}{$x$} \\
\hline & $30^{\circ} \mathrm{C}$ & $40^{\circ} \mathrm{C}$ & $50^{\circ} \mathrm{C}$ & $60^{\circ} \mathrm{C}$ & $30^{\circ} \mathrm{C}$ & $40^{\circ} \mathrm{C}$ & $50^{\circ} \mathrm{C}$ & $60^{\circ} \mathrm{C}$ & $30^{\circ} \mathrm{C}$ & $40^{\circ} \mathrm{C}$ & $50^{\circ} \mathrm{C}$ & $60^{\circ} \mathrm{C}$ \\
\hline$n$-Pentane & 58 & 43 & 30 & 24 & 7.63 & 7.74 & 8.28 & 8.17 & 0.66 & 0.68 & 0.74 & 0.73 \\
\hline$n$-Hexane & 177 & 115 & 80 & 60 & 6.77 & 7.23 & 7.43 & 7.38 & 0.59 & 0.66 & 0.69 & 0.68 \\
\hline$n$-Heptane & 494 & 322 & 210 & 145 & 6.62 & 6.65 & 6.91 & 6.98 & 0.61 & 0.61 & 0.65 & 0.66 \\
\hline$n$-octane & 1418 & 859 & 545 & 352 & 6.36 & 6.44 & 6.49 & 6.64 & 0.59 & 0.61 & 0.61 & 0.64 \\
\hline 2-Methylpentane & 116 & 82 & 59 & 43 & 7.49 & 7.49 & 7.60 & 7.82 & 0.68 & 0.68 & 0.70 & 0.73 \\
\hline Cyclopentane & 149 & 104 & 78 & 59 & 4.81 & 4.98 & 4.94 & 4.98 & 0.37 & 0.41 & 0.40 & 0.41 \\
\hline Cyclohexane & 397 & 259 & 204 & 136 & 4.70 & 4.92 & 4.40 & 4.78 & 0.39 & 0.44 & 0.33 & 0.41 \\
\hline Methylcyclohexane & 703 & 455 & 309 & 217 & 4.72 & 4.84 & 4.88 & 4.90 & 0.39 & 0.41 & 0.42 & 0.42 \\
\hline Benzene & 549 & 347 & 247 & 183 & 3.74 & 4.01 & 3.93 & 3.81 & 0.29 & 0.36 & 0.34 & 0.31 \\
\hline Toluene & 1655 & 1025 & 665 & 446 & 3.41 & 3.53 & 3.62 & 3.70 & 0.18 & 0.21 & 0.24 & 0.26 \\
\hline Ethylbenzene & 4140 & 2472 & 1525 & 988 & 3.40 & 3.48 & 3.57 & 3.61 & 0.18 & 0.20 & 0.22 & 0.24 \\
\hline 1-Hexene & 170 & 119 & 81 & 59 & 5.91 & 5.93 & 6.34 & 6.45 & 0.49 & 0.49 & 0.55 & 0.57 \\
\hline Tetrahydrofuran & 431 & 284 & 188 & 150 & 3.07 & 3.22 & 3.46 & 3.18 & 0.10 & 0.15 & 0.22 & 0.14 \\
\hline
\end{tabular}

n.a.: not available.

ple, Figs. 3 and 4 show the above mentioned plots at $30^{\circ} \mathrm{C}$. The solubility parameter values are shown in Table 3.

As it was expected the influence of the temperature over the solubility parameter is almost negligible.

\subsection{Consistency test: heat of vaporization of the solvents}

From the values of the activity coefficient of the solvents at several temperatures, the values of their heats of vaporization

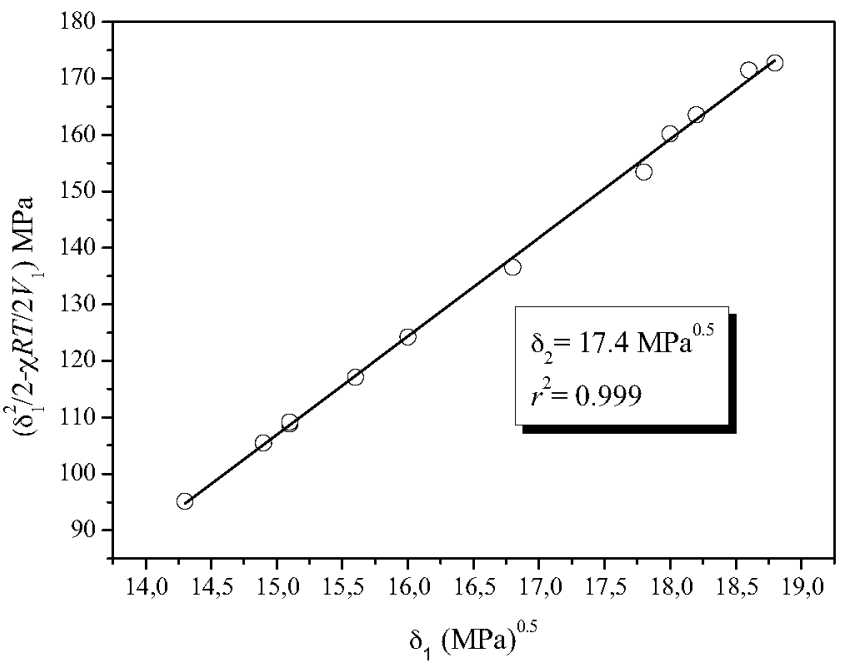

Fig. 3. Plot for the calculation of $\mathrm{C} 411$ solubility parameter at $30^{\circ} \mathrm{C}$.
( $\triangle_{\mathrm{vap}} H_{1}$ ) were determined (Eqs. (10)-(13)). The results are summarized in Table 4 . As it can be observed, the difference between the experimental and estimated values is always lower than $5 \%$

\subsection{NRTL binary interaction parameters}

The Flory-Huggins parameter allows estimating $P-w_{2}$ (pressure $v s$, polymer mass fraction) equilibrium data of each solvent

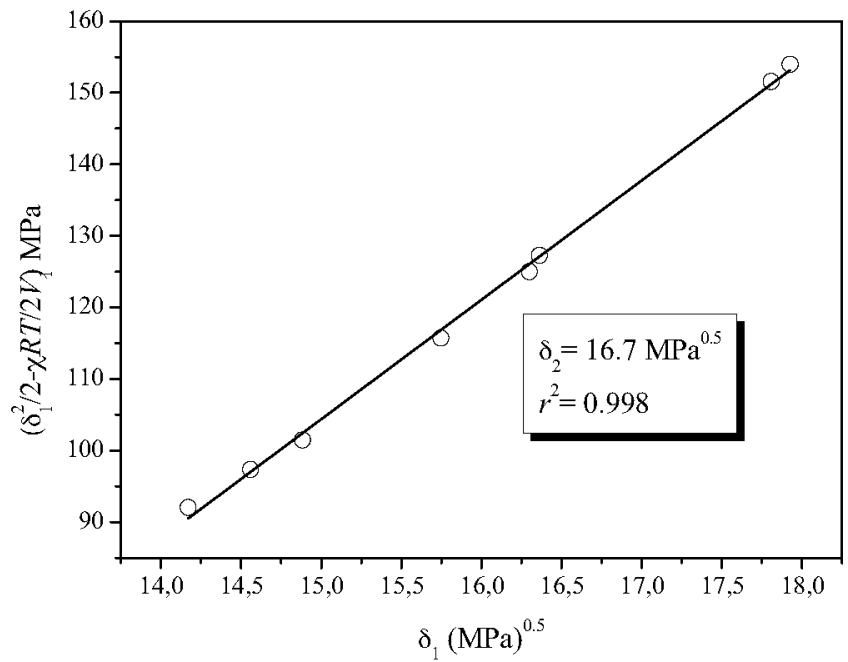

Fig. 4. Plot for the calculation of $\mathrm{C} 501$ solubility parameter at $30^{\circ} \mathrm{C}$. 
Initial data: $P_{1}^{0}, \phi_{1}, \chi$

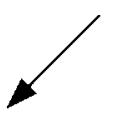

Flory-Huggins equation

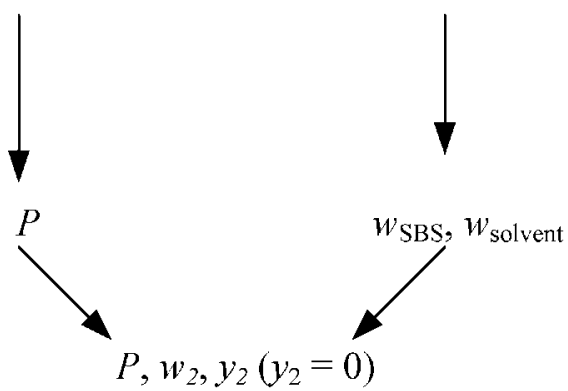

Fig. 5. Procedure to obtain $P-w_{i}$ data from FH parameters.

(1)-rubber (2) mixtures, according to a procedure which has already been described in the literature [2], and it is shown in Fig. 5 .

Following this procedure by fixing a value of the polymer volume fraction $\left(\phi_{2}\right)$ and using rubber and solvent densities, in a first step the mass fraction of both compounds $\left(w_{1}, w_{2}=1-w_{1}\right)$ can be calculated. On a second step, the vapor pressure of a polymer-solvent mixture $(P)$ with a polymer volume fraction $\phi_{2}$ can also be obtained from the pure solvent vapor pressure value $\left(P_{1}^{0}\right)$, the polymer-solvent interaction parameter $(\chi)$ and the polymer volume fraction $\left(\phi_{2}\right)$, by applying Flory-Huggins equation (Eq. (6)). This way, and considering that the amount of rubber in the vapor phase is negligible $\left(y_{2} \approx 0\right)$, an estimated $P$ - $w_{2}$ pair can be established at each temperature. Finally, the overall data set (at the four temperatures) is now suitable to be fitted to NRTL model.

Once the estimated dataset has been obtained, the infinite dilution mass-based or molar-based activity coefficient of the solvent can be calculated, taking into account that the fugacity value should be the same in both liquid and vapor phases (Eq. (14)).

$P y_{1}=p_{1}=P_{1}^{0} x_{1}\left(\gamma_{1}^{\infty}\right)_{\text {calc }}=P_{1}^{0} w_{1}\left(\Omega_{1}^{\infty}\right)_{\text {calc }}$

In this last equation, $x_{1}$ is the mole fraction of the solvent in the liquid phase, $\left(\gamma_{1}^{\infty}\right)_{\text {calc }}$ is the calculated infinite dilution solvent activity coefficient, and $\left(\Omega_{1}^{\infty}\right)_{\text {calc }}$ is the calculated infinite dilution mass-based solvent activity coefficient.

Afterwards, each estimated rubber-solvent dataset was fitted to the well-known NRTL activity coefficient model [14] according to Eq. (15), with the aim of obtaining the binary interaction parameters. These parameter values can be employed to determine the mass-based solvent activity coefficients, $\left(\Omega_{1}\right)_{\mathrm{NRTL}}$, which will allow the prediction of the phase equilibrium behavior at high rubber

Table 3

Solubility parameter values.

\begin{tabular}{lll}
\hline Temperature $(\mathrm{C})$ & \multicolumn{2}{l}{ Solubility parameter $\left(\mathrm{MPa}^{1 / 2}\right)$} \\
\cline { 2 - 3 } & C411 polymer & C501 polymer \\
\hline 30 & 17.4 & 16.7 \\
40 & 17.3 & 16.5 \\
50 & 17.4 & 16.3 \\
60 & 17.4 & 16.6 \\
\hline
\end{tabular}

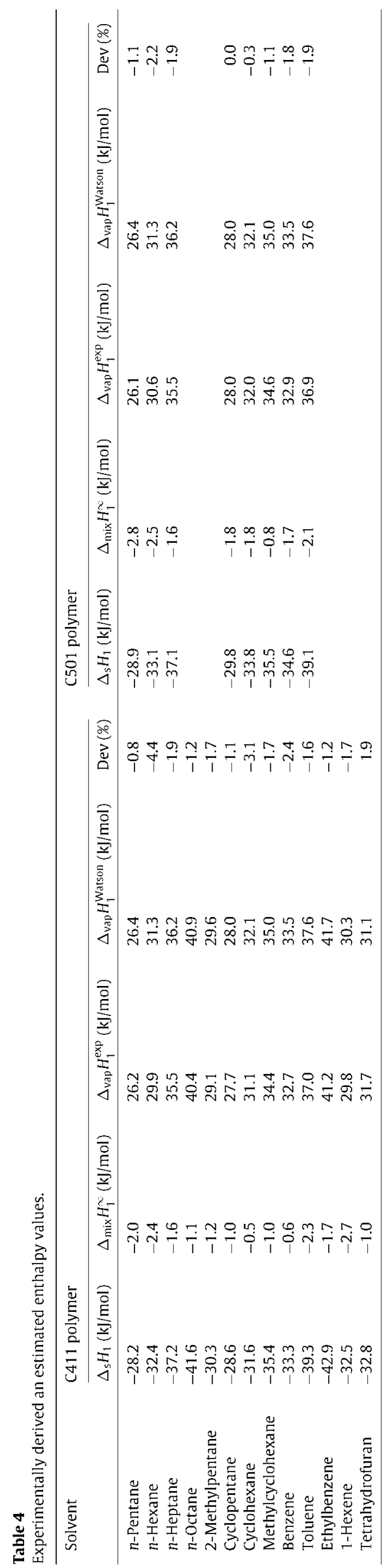


Table 5

Estimated equilibrium data for methylcyclohexane (1)-rubber (2) mixtures.

\begin{tabular}{|c|c|c|c|c|c|c|c|c|c|}
\hline \multirow[t]{2}{*}{ Temp. $\left({ }^{\circ} \mathrm{C}\right)$} & \multirow[t]{2}{*}{$\phi_{2}$} & \multicolumn{4}{|c|}{ C411 rubber } & \multicolumn{4}{|c|}{ C501 rubber } \\
\hline & & $P(\mathrm{kPa})$ & $\left(\Omega_{1}^{\infty}\right)_{\text {calc }}$ & $\left(\Omega_{1}^{\infty}\right)_{\mathrm{IGC}}$ & $\left(\Omega_{1}^{\infty}\right)_{\text {NTRL }}$ & $P(\mathrm{kPa})$ & $\left(\Omega_{1}^{\infty}\right)_{\text {calc }}$ & $\left(\Omega_{1}^{\infty}\right)_{\mathrm{IGC}}$ & $\left(\Omega_{1}^{\infty}\right)_{\mathrm{NTRL}}$ \\
\hline 30 & 0.99 & 0.28 & 4.68 & 4.70 & 4.70 & 0.44 & 7.37 & 7.84 & 7.39 \\
\hline 40 & 0.99 & 0.44 & 4.85 & 4.92 & 4.82 & 0.68 & 7.50 & 7.97 & 7.47 \\
\hline 50 & 0.99 & 0.68 & 4.96 & 4.40 & 4.94 & 1.03 & 7.55 & 8.03 & 7.54 \\
\hline 60 & 0.99 & 0.99 & 5.03 & 4.78 & 5.05 & 1.50 & 7.60 & 8.08 & 7.61 \\
\hline
\end{tabular}

Table 6

Binary interaction parameters for rubber-solvent mixtures.

\begin{tabular}{|c|c|c|c|c|c|c|}
\hline \multirow[t]{2}{*}{ Solvent } & \multicolumn{3}{|c|}{ C411 polymer } & \multicolumn{3}{|c|}{ C501 polymer } \\
\hline & $\Delta g_{12} / R$ & $\Delta g_{21} / R$ & $\alpha$ & $\Delta g_{12} / R$ & $\Delta g_{21} / R$ & $\alpha$ \\
\hline$n$-Pentane & 891.81 & -556.25 & 0.3 & 695.05 & -494.84 & 0.3 \\
\hline$n$-Hexane & 894.41 & -527.71 & 0.3 & 812.01 & -427.38 & 0.3 \\
\hline$n$-Heptane & 693.99 & -478.68 & 0.3 & 723.48 & -329.66 & 0.3 \\
\hline$n$-Octane & 588.84 & -429.22 & 0.3 & & & \\
\hline 2-Methylpentane & 614.64 & -470.28 & 0.3 & & & \\
\hline Cyclopentane & -76.74 & -278.97 & 0.3 & -58.00 & -260.83 & 0.3 \\
\hline Cyclohexane & 56.05 & -250.15 & 0.3 & 81.01 & -268.23 & 0.3 \\
\hline Methylcyclohexane & 155.73 & -367.94 & 0.3 & 151.29 & -216.00 & 0.3 \\
\hline Benzene & -81.92 & -313.28 & 0.3 & -70.48 & -255.05 & 0.3 \\
\hline Toluene & -65.40 & -297.52 & 0.3 & 220.93 & -407.37 & 0.3 \\
\hline Ethylbenzene & -43.06 & -275.98 & 0.3 & & & \\
\hline 1-Hexene & 873.86 & -587.26 & 0.3 & & & \\
\hline Tetrahydrofuran & -144.99 & -339.45 & 0.3 & & & \\
\hline
\end{tabular}

compositions. The adjustments were performed by minimizing the objective function described in Eq. (16).

$$
\begin{aligned}
& \ln \left(\gamma_{1}\right)_{\mathrm{NRTL}}=x_{2}^{2}\left[\tau_{21}\left(\frac{G_{21}}{x_{1}+x_{2} G_{21}}\right)^{2}+\left(\frac{\tau_{12} G_{12}}{\left(x_{1} G_{12}+x_{2}\right)^{2}}\right)\right] \\
& =\ln \left(\frac{w_{1}\left(\Omega_{1}\right)_{\mathrm{NRTL}}}{x_{1}}\right) \\
& G_{12}=\exp \left(-\alpha_{12} \tau_{12}\right), \quad G_{21}=\exp \left(-\alpha_{12} \tau_{21}\right) \\
& \tau_{12}=\left(\frac{\Delta g_{12}}{R T}\right), \quad \tau_{21}=\left(\frac{\Delta g_{21}}{R T}\right) \\
& \text { O.F. }=\sum_{i}\left[\left(\Omega_{1}\right)_{\text {calc }}-\left(\Omega_{1}\right)_{\mathrm{NRTL}}\right]^{2}
\end{aligned}
$$

As an example, Table 5 shows the estimated datasets for the mixtures of both rubbers and methylcyclohexane, along with the calculated (Eq. (14)) mass-based solvent activity coefficients, $\left(\Omega_{1}^{\infty}\right)_{\text {alc }}$. These last values are compared with the ones obtained directly from the IGC measurements, $\left(\Omega_{i}^{\infty}\right)_{\text {IGC }}$ and with the ones obtained with the regression of the estimated data sets to NRTL model $\left(\Omega_{i}^{\infty}\right)_{\mathrm{NRTL}}$. As it can be seen, there is not any appreciable difference between the three values. Due to the Flory-Huggins parameters were obtained at solvent infinite dilution, a polymer volume fraction close to one was assumed $\left(\phi_{2}=0.99\right)$.

Table 6 shows the fitted binary interaction parameters for all the mixtures tested. These interaction parameters have a great importance in order to model, for example, the separation steps in the process of obtaining the rubber, at high rubber compositions [2]. Table 7 shows the values of the root-mean-square deviations (RMSD) of the mass-based solvent activity coefficient, which were calculated with Eq. (17). The greater deviation is less than 0.35 .

$\operatorname{RMSD}\left(\Omega_{1}\right)=\left\{\frac{1}{N} \sum_{i}\left[\left(\Omega_{1}\right)_{\mathrm{calc}}-\left(\Omega_{1}\right)_{\mathrm{NRTL}}\right]^{2}\right\}$

\subsection{Comparison with previous results}

By gathering all the information regarding the studied SBS rubbers and which is summarized in Table 8 , it can be observed that there are noticeable differences between the $\chi$ parameters determined by both IV and IGC techniques. Due to IV and IGC techniques are employed in completely different ranges of polymer composition, the differences between the Flory-Huggins parameters obtained by IV and IGC, can be related to the influence of the composition over the Flory-Huggins parameter. This implies that the interactions between the polymer and the solvent (which are measured by means of the Flory-Huggins parameter) are changing with

Table 7

Solvent activity coefficient RMSD for all rubber-solvent mixtures.

\begin{tabular}{|c|c|c|c|c|}
\hline \multirow{2}{*}{$\begin{array}{l}\text { Polymer } \\
\text { Technique }\end{array}$} & \multicolumn{2}{|c|}{$\begin{array}{l}\text { C501 (SBS rubber lineal } \\
\text { not hydrogenated) }\end{array}$} & \multicolumn{2}{|c|}{$\begin{array}{l}\text { C411 (SBS rubber radial } \\
\text { not hydrogenated) }\end{array}$} \\
\hline & IV [9] & IGC & IV [9] & $\mathrm{IGC}$ \\
\hline$n$-Pentane & n.a. & 0.780 & n.a. & 0.590 \\
\hline$n$-Hexane & n.a. & 0.910 & n.a. & 0.590 \\
\hline$n$-Heptane & n.a. & 1.090 & n.a. & 0.660 \\
\hline Cyclopentane & 0.395 & 0.500 & 0.395 & 0.370 \\
\hline Cyclohexane & 0.432 & 0.680 & 0.433 & 0.390 \\
\hline Methylcyclohexane & 0.490 & 0.850 & 0.489 & 0.390 \\
\hline Benzene & 0.389 & 0.500 & 0.391 & 0.290 \\
\hline Toluene & 0.360 & 0.570 & 0.361 & 0.180 \\
\hline
\end{tabular}

\begin{tabular}{lll}
\hline Solvent & C411 polymer & C501 polymer \\
\hline$n$-Pentane & 0.12 & 0.02 \\
$n$-Hexane & 0.12 & 0.01 \\
$n$-Heptane & 0.05 & 0.03 \\
$n$-Octane & 0.03 & \\
2-Methylpentane & 0.07 & 0.08 \\
Cyclopentane & 0.06 & 0.02 \\
Cyclohexane & 0.21 & 0.02 \\
Methylcyclohexane & 0.02 & 0.06 \\
Benzene & 0.33 & 0.04 \\
Toluene & 0.02 & \\
Ethylbenzene & 0.01 & \\
1-Hexene & 0.08 & \\
Tetrahydrofuran & 0.14 & \\
\hline
\end{tabular}

Table 8

Flory-Huggins interaction parameters of all the systems polymer-solvent by IV and IGC.

n.a.: not available. 
Table 9

Solubility parameter of SBS polymers by IV and IGC.

\begin{tabular}{lll}
\hline & $\delta_{2}(\mathrm{MPa})^{0.5}$ by IV & $\delta_{2}(\mathrm{MPa})^{0.5}$ by IGC \\
\hline C501 (linear SBS not hydrogenated) & 17.6 & 16.7 \\
C411 (radial SBS not hydrogenated) & 17.6 & 17.4 \\
\hline
\end{tabular}

the relative amount of both components in the mixture. Table 8 also shows that, when the amount of rubber is low (IV measurements), its structure (radial, C411 or linear, C501) is not the critical point affecting the interactions with the solvents studied in this work (as it can be seen, for the same solvent, the obtained values of the $\chi$ parameter by means of IV are very close). On the other hand, when the amount of rubber is high (IGC measurements), the polymer structure does affect the interactions with the studied solvents (as it can be seen, for a fixed solvent, the IGC obtained value of the $\chi$ parameter in its mixture with $C 411$ rubber, is different from the obtained value in its mixture with C501 rubber).

The influence of the polymer composition over the polymer-solvent interactions can also be observed in the experimental values of the rubber solubility parameters which have been measured for the two polymers (Table 9 ). In this case, the obtained values by IGC are lower than those obtained by IV. This means that, according to the former technique, there is a higher compatibility of both rubbers with the lightest solvents (the ones with the lowest solubility parameters values).

\section{Conclusions}

The Flory-Huggins interaction parameters have been determined for binary mixtures of several solvents with two SBS triblock copolymers. The influence of the solvent class over this parameter shows that the mixtures with aromatic and cyclic compounds have the lowest values of the Flory-Huggins parameters, while the highest values correspond to the mixtures with paraffin-type compounds. This means that the aromatic and cyclic solvents (cyclohexane, methylcyclohexane, benzene and toluene) are the most compatible ones with both $\mathrm{C} 411$ and $\mathrm{C501}$ rubbers. The influence of the temperature over Flory-Huggins parameter is almost negligible.

From the Flory-Huggins parameters the infinite dilution solvent activity coefficients could be calculated. These last values were fitted to the NRTL model; in all cases, the adjustments were good enough, so that the calculated binary interaction parameters can be employed to model, for example, the separation steps in the process of obtaining the rubber at high rubber compositions.

The solubility parameters of these two SBS triblock copolymers were also determined. The obtained values are slightly smaller than the ones obtained by means of IV technique.

$\begin{array}{ll}\text { List of symbols } \\ a_{i} & \text { activity of } i \\ B_{11} & \text { solvent second term of the Virial EOS, } \mathrm{cm}^{3} / \mathrm{mol} \\ f_{i}^{0} & \text { standard fugacity of the } i \text { component, } \mathrm{Pa} \\ F & \text { carrier gas flow rate, } \mathrm{cm}^{3} / \mathrm{s} \\ j & \text { retention volume correction factor } \\ M_{i} & i \text { average molecular weight }\end{array}$

$p_{1}^{s} \quad$ solvent vapor pressure, $\mathrm{Pa}$

$P \quad$ pressure, $\mathrm{Pa}$

$P_{i} \quad$ inlet column pressure, $\mathrm{Pa}$

$P_{0} \quad$ outlet column pressure, $\mathrm{Pa}$

$r$ molar volume of polymer to molar volume of solvent ratio

$t_{m} \quad$ inert component retention time, $s$

$t_{r} \quad$ solvent retention time, $\mathrm{s}$

$V_{g} \quad$ retention volume, $\mathrm{cm}^{3} / \mathrm{g}$

$V_{i} \quad$ molar volume of $i, \mathrm{~cm}^{3} / \mathrm{mol}$

$W$ amount of polymer packed in the column, $g$

$\delta_{i} \quad$ solubility parameter of $i, \mathrm{MPa}^{1 / 2}$

$\Delta_{\text {mix }} H_{1}^{\infty}$ partial molar heat of mixing, $\mathrm{kJ} / \mathrm{mol}$

$\Delta_{S} H_{1}$ heat of solution, $\mathrm{kJ} / \mathrm{mol}$

$\Delta_{\mathrm{vap}} H_{1}$ heat of vaporization, $\mathrm{kJ} / \mathrm{mol}$

$\phi_{i} \quad$ volume fraction of $i$

$\chi \quad$ polymer-solvent interaction parameter

$\gamma_{i}^{\infty} \quad$ infinite dilution activity coefficient of $i$

$\Omega_{i}^{\infty} \quad$ mass-based infinite dilution activity coefficient of $i$

$\rho_{i} \quad$ density of $i, \mathrm{~g} / \mathrm{cm}^{3}$

\section{Acknowledgements}

The authors gratefully acknowledge the REPSOL-YPF for the supply of the polymers. Financial support from Spanish Education Ministry (AP2006-02300) is also acknowledged.

\section{References}

[1] J.N. Henderson, Styrene-Butadiene Rubbers. Rubber Technology, third ed. Kluwer Academic Publisher, Dordrecht, 1999.

[2] G. Ovejero, M.D. Romero, E. Dǐ̌ez, I. Dī̌az, P. Peǐrez, Ind. Eng. Chem. Res. 48 (2009) $7713-7723$.

[3] G.M. Bristow, W.F. Watson, Trans. Faraday Soc. 54 (1958) 1731-1741

[4] K. Ito, J.E. Guillet, Macromolecules 12 (1979) 1163-1167.

[5] Y. Liu, B. Shi, Polym. Bull. 61 (2008) 501-509.

[6] R. Ravindra, K.R. Krovvidi, A.A. Khan, Carbohyd. Polym. 36 (1998) 121-127.

[7] G. Ovejero, P. Pérez, M.D. Romero, I. Díaz, E. Díez, Eur. Polym. J. 43 (2007) $1444-1449$.

[8] G. Ovejero, M.D. Romero, E. Díez, I. Díaz, Eur. Polym. J. 45 (2) (2009) 590-594.

[9] G. Ovejero, M.D. Romero, E. Díez, I. Díaz, Eur. Polym. J. 46 (2010) 2261-2268.

[10] P.J. Flory, J. Chem. Phys. 9 (1941) 660-661.

[11] W.R. Krigbaum, D.O. Geymer, J. Am. Chem. Soc. 81 (1959) 1859-1868.

[12] I. Noda, Y. Higo, N. Ueno, T. Fujimoto, Macromolecules 17 (1984) 1055-1059.

[13] R.F. Blanks, J.M. Prausnitz, Ind. Eng. Chem. Fundam. 3 (1964) 1-8.

[14] H. Renon, J.M. Prausnitz, AiChE J. 14 (1968) 135-144.

[15] S.K. Papadopoulou, G. Dritsas, I. Karapanagiotis, I. Zuburtikudis, C. Panayiootou, Eur. Polym. J. 46 (2010) 2002-2008.

[16] M.K. Kozłowska, U. Domańska, M. Lempert, M. Rogalski, J. Chromatogr. A 1068 (2005) 293-305.

[17] J.R. Conder, C.L. Young, Physicochemical Measurement by Gas Chromatography, first ed., John Wiley \& Sons, New York, 1979

[18] C.F. Spencer, R.P. Danner, J. Chem. Eng. Data 17 (1972) 236-241.

[19] C. Tsonopoulos, AiChE J. 20 (1974) 263-272.

[20] R.C. Reid, J.M. Prausnitz, B.E. Poling, The Properties of Gases and Liquids, fourth ed., McGraw-Hill, New York, 1987.

[21] I.H. Romdhane, A. Plana, S. Hwang, R.P. Danner, J. Appl. Polym. Sci. 45 (1992) $2049-2056$

[22] J.S. Vrentas, C.M. Vrentas, I.H. Romdhane, Macromolecules 26 (1993) 6670-6672.

[23] J. Hildebrand, R. Scout, Regular Solutions, first ed., Prentice Hall, Englewood Cliffs, 1962.

[24] J. Brandrup, E.H. Immergut, E.A. Grulke, Poymer Handbook, fourth ed., John Wiley \& Sons, New York, 1999

[25] K.M. Watson, Ind. Eng. Chem. 35 (1943) 398-401. 